\title{
META ANALISIS: PENGARUH MODEL PROBLEM BASED LEARNING TERHADAP MOTIVASI BELAJAR DAN KETERAMPILAN PROSES SAINS FISIKA SISWA SMA
}

\author{
Nurul Azmi ${ }^{11}$, Asrizal'1), Fatni Mufit'1) \\ 1)Program Studi Magister Pendidikan Fisika, FMIPA, Universitas Negeri Padang, Padang, Sumatera Barat, Indonesia
}

Corresponding author : Nurul Azmi

E-mail : nurul.azmi257@gmail.com

Diterima 13 Agustus 2021, Direvisi 16 Juli 2021, Disetujui 16 Juli 2021

\begin{abstract}
ABSTRAK
Penelitian ini bertujuan untuk 1) menganalisis pengaruh model problem based learning ditinjau dari motivasi belajar fisika, 2) menganalisis pengaruh model problem based learning ditinjau dari keterampilan proses sains siswa, 3) menganalisis pengaruh model problem based learning terhadap motivasi belajar dan keterampilan proses sains siswa ditinjau dari tingkatan kelas, dan 4) menganalisis pengaruh model problem based learning terhadap motivasi belajar dan keterampilan proses sains siswa ditinjau dari materi pembelajaran. Jenis penelitian yang diterapkan pada penelitian ini adalah meta analisis. Hasil dari penelitian ini yaitu : 1) model pembelajaran problem based learning memberikan pengaruh terhadap motivasi belajar fisika siswa SMA dengan rata-rata effect size 0,73 kategori sedang, 2) model pembelajaran problem based learning memberikan pengaruh terhadap keterampilan proses sains siswa dengan effect size 0,62 kategori sedang, 3) model pembelajaran problem based learning memberikan pengaruh terhadap motivasi belajar dan keterampilan proses sains fisika pada tingkatan kelas X, XI dan XII dengan effect size 0,86 kategori tinggi, 0,47 kategori sedang dan 0,28 kategori sedang, dan 4) model pembelajaran problem based learning memberikan pengaruh terhadap motivasi belajar dan keterampilan proses sains pada materi listrik dinamis dengan effect size 2,02 kategori tinggi.
\end{abstract}

Kata kunci: Problem Based Learning; Motivasi; Keterampilan Proses Sains.

\begin{abstract}
This study aims to 1) analyze the effect of the problem based learning model in terms of motivation to learn physics, 2) analyze the effect of the problem based learning model in terms of students' science process skills, 3) analyze the effect of the problem based learning model on students' learning motivation and science process skills in terms of from the grade level, and 4) analyzing the effect of the problem based learning model on students' learning motivation and science process skills in terms of learning materials. The type of research applied in this study is a meta-analysis. The results of this study are: 1 ) the problem based learning model has an influence on the motivation to learn physics for high school students with an average effect size of 0.73 in the medium category, 2) the problem based learning model has an effect on students' science process skills with an effect size 0.62 medium category, 3) problem based learning learning model has an influence on learning motivation and physics science process skills at the level of class $\mathrm{X}, \mathrm{XI}$ and $\mathrm{XI}$ with an effect size of 0.86 high category, 0.47 medium category and 0.28 category medium, and 4 ) the problem based learning model has an influence on learning motivation and science process skills on dynamic electrical material with an effect size of 2.02 in the high category.
\end{abstract}

Keywords: Problem Based Learning; Motivation; Science Process Skills.

\section{PENDAHULUAN}

Kehidupan pada abad 21 menuntut berbagai keterampilan yang harus dikuasai oleh setiap individu (Fatni Mufit dan Asrizal, 2020). Abad 21 juga menyediakan berbagai informasi yang tersedia dimana saja dan kapan saja sehingga diperoleh semua orang di penjuru dunia tanpa terkecuali. Perkembangan ilmu pengetahuan dan teknologi (IPTEK) begitu pesat, tak ada batasan ruang lagi untuk kita saling berkomunikasi. Dengan perkembangan IPTEK berimbas pada tantangan dan persaingan global yang dihadapi oleh setiap negara. Di Indonesia perlu terciptanya sumber daya manusia yang berkualitas untuk mampu bersaing dengan masyarakat luas. Dengan dasar ini, pendidikan abad ke-21 seharusnya mampu mengembangkan kompetensi siswa pada pengetahuan, keterampilan, sikap dan nilai unggul (Asrizal,2018). 
Pendidikan sangat penting bagi kehidupan dan kemajuan bangsa, karena berawal dari pendidikan terciptalah sumber daya manusia yang tangguh dan mampu mengadakan perubahan untuk mendukung pembangunan negara ke arah yang lebih maju. Sejak di dalam kandungan, orang tua sudah mengenalkan pendidikan kepada anaknya, setelah lahir kemudian tumbuh dan berkembang, pembelajaran kepada anak diberikan melalui jenjang pendidikan dasar, pendidikan menengah hingga perguruan tinggi. Pada hakikatnya pendidikan diharapkan menghasilkan siswa yang memiliki kualitas untuk hidup sebagai individu yang kreatif, inovatif, cerdas, dan kompeten secara global (Usmeldi, 2017).

Struktur kurikulum tingkat SMA 2013 berdasarkan Peraturan Menteri Pendidikan dan Kebudayaan Nomor 36 Tahun 2018 menetapkan bahwa fisika merupakan mata pelajaran wajib bagi golongan $\mathrm{C}$ yang merupakan mata pelajaran kurikuler. Mata pelajaran fisika bertujuan untuk mengembangkan sikap, kompetensi pengetahuan, dan kompetensi keterampilan siswa sesuai dengan minat, bakat atau kemampuan akademiknya dalam menganalisis fenomena kehidupan dan lingkungan (Fatni Mufit dan Asrizal, 2021).

Fisika sebagai ilmu bidang sains merupakan salah satu mata pelajaran yang berhubungan dengan alam. Menurut Wardhani, (2012), penekanan pembelajaran Fisika harus relevan dengan kehidupan sehari-hari, supaya pelajaran Fisika yang diperoleh akan bermanfaat, dan akan mempunyai peran yang penting bagi siswa yang mengaplikasikannya dalam kehidupan sehari-hari. Selanjutnya akan berdampak dalam menciptakan sumber daya manusia yang bermutu.

Hasil dilakukan studi awal yaitu dengan membaca dari beberapa artikel literature yang berkaitan dengan pengaruh model problem based learning terhadap motivasi belajar dan keterampilan proses sains fisika siswa SMA diperoleh kondisi nyata di lapangan. Kondisi nyatanya yaitu siswa cenderung menerima apa saja yang dijelaskan oleh guru tanpa harus mengetahui makna dari pelajaran tersebut. Siswa juga cenderung menghafal pengertian dan rumus, pendekatan pembelajarannya kurang berhubungan dengan fenomena alam, kehidupan sehari-hari, dan perkembangan teknologi. Hal ini menyebabkan siswa pasif dan kurang termotivasi dalam belajar, siswa menganggap bahwa fisika itu sulit dan membosankan, sehingga menyebabkan kurangnya motivasi siswa dalam belajar fisika dan menyebabkan siswa malas belajar.
Salah satu upaya meningkatkan motivasi belajar siswa adalah dengan menerapkan model pembelajaran Problem Based Learning (PBL). Pada model problem based learning pembelajaran dilakukan dengan pemberian masalah kepada siswa yang sesuai dengan konteks lingkungan kehidupan sehingga memberikan pengalaman yang dapat digunakan sebagai bahan atau materi untuk memperoleh pengertian serta bisa dijadikan pedoman dan tujuan belajar untuk meningkatkan hasil belajar secara optimal. Lasmawan (2010) mengemukakan beberapa keunggulan dari model problem based learning, antara lain: problem based learning merupakan teknik yang baik dalam memahami isi pelajaran, dapat menantang kemampuan siswa serta memberikan kepuasan untuk menemukan pengatahuan baru bagi siswa, dapat meningkatkan aktivitas siswa dalam kegiatan pembelajaran, dapat membantu siswa untuk mentransfer pengetahuan untuk memahami masalah dalam kehidupan nyata, dapat membantu siswa mengembangkan pengetahuan barunya dan bertanggung jawab dalam pembelajaran yang mereka lakukan.

Sejalan dengan teori menurut Arends (2008), problem based learning merupakan model pembelajaran yang menyuguhkan berbagai situasi bermasalah yang autentik dan bermakna kepada siswa, yang dapat berfungsi sebagai batu loncatan untuk investigasi dan penyelidikan. Problem based learning membantu siswa untuk mengembangkan keterampilan proses sains dan keterampilan menyelesaikan masalah. Sehingga dapat meningkatkan motivasi belajar siswa.

Keterampilan proses sains adalah keterampilan yang dapat digunakan untuk memahami fenomena apa saja yang terjadi. Keterampilan ini diperlukan untuk memperoleh, mengembangkan dan menerapkan konsep, prinsip dan hukum yang ada pada sains (Toharudin, dkk: 2011). Maradona (2013) mendefinisikan keterampilan proses sains merupakan kemampuan siswa dalam melakukan metode ilmiah untuk memahami, mengembangkan sains serta menemukan ilmu pengetahuan.

Kemampuan keterampilan proses sains siswa Indonesia masih tergolong rendah. Hal ini dapat dibuktikan dari data TIMSS (Trends in International Mathematics and Science Study) dan PISA (Programme for International Student Assessment). Berdasarkan data TIMSS tahun 2015 menunjukkan bahwa Indonesia memperoleh skor 397 dan menduduki peringkat 44 dari 47 Negara. Skor yang diperoleh Indonesia masih cukup jauh dari skor standard TIMSS, di mana skor standard TIMSS yaitu 
sebesar 500. Di dalam butir soal TIMSS yang disajikan terdapat soal yang digunakan untuk mengukur kemampuan siswa pada aspek keterampilan proses sains seperti mengidentifikasi, melengkapi tabel, membaca tabel dan diagram, dan menginterpretasi data (IEA, 2016).

Selain itu, berdasarkan data PISA pada tahun 2015 menunjukkan bahwa Indonesia memperoleh skor 403 dan menduduki peringkat ke 62 dari 70 Negara. Skor Indonesia masih sangat jauh dari skor rata-rata OECD, di mana skor OECD yaitu sebesar 493 (OECD, 2016). Dalam butir soal PISA juga disajikan beberapa soal yang digunakan untuk mengukur kemampuan siswa pada aspek keterampilan menginterpretasi data, membaca tabel, melakukan pembuktian secara ilmiah, dan mendesain penyelidikan ilmiah (PISA, 2015).

Berdasarkan permasalahan di atas, maka analisis effect size ini bertujuan untuk: 1) menganalisis pengaruh model problem based learning ditinjau dari motivasi belajar fisika, 2) menganalisis pengaruh model problem based learning ditinjau dari keterampilan proses sains siswa, 3) menganalisis pengaruh model problem based learning terhadap motivasi belajar dan keterampilan proses sains siswa ditinjau dari tingkatan kelas, dan 4) menganalisis pengaruh model problem based learning terhadap motivasi belajar dan keterampilan proses sains siswa ditinjau dari materi pembelajaran.

\section{METODE PENELITIAN}

Penelitian ini menggunakan metode analisis effect size. Effect size merupakan ukuran mengenai besarnya efek suatu variabel terhadap variabel lain, kemudian besarnya perbedaan maupun hubungan suatu sampel. Analisis dibuat dengan cara merangkum data dari beberapa penelitian berupa penetapan tema penelitian, mengumpulkan sumber artikel, memilih tempat publikasi, mencatat data dari sumber penelitian, menentukan effect size serta membuat kesimpulan atas data analisis yang diperoleh. Kelebihan dari penelitian analisis ini yaitu menggabungkan beberapa hasil penelitian kuantitatif, mampu memberikan gambaran terhadap hasil penelitian dengan baik, serta objektif dalam menggambarkan data hasil penelitian tanpa ada unsur subjektivitas dari peneliti.

Tahapan analisis dapat dijelaskan sebagai berikut:

\section{Tahap persiapan}

a. Mengumpulkan data dari Google Scholar rentang waktu 2016-2020, sehingga diperoleh sebanyak 18 artikel terdapat pada Tabel 2. b. Variabel penelitian pada artikel ini terdiri dari dua variabel yaitu variabel bebas pada model problem based learning, sedangkan variabel terikatnya pada motivasi belajar dan keterampilan proses sains.

2. Tahap pelaksanaan

a. Mengumpulkan data melalui sumber literatur dari 1 Mei-Juni 2021.

b. Meresume data artikel penelitian berupa variabel penelitian, tujuan penelitian, motivasi belajar, keterampilan proses sains, tingkatan kelas dan materi pembelajaran.

c. Pengkodean penelitian untuk mempermudah menganalisis.

d. Menganalisis effect size dari hasil pengumpulan artikel penelitian.

e. Menyimpulkan hasil analisis data.

3. Teknik analisis data

a. Menganalisis domain effect size dari penelitian berupa:

- Mean pre test

- Mean post test

- Standar deviasi eksperimen

- Standar deviasi kontrol

- Mean eksperimen

- Mean kontrol

- Koefisien nilai t

b. Menganalisis pengaruh antar variabel. Effect size dapat ditentukan dalam parameter statistik berikut ini (Becker, 2011):

a. Rata-rata pada satu kelompok

$$
E S=\frac{\bar{x}_{\text {postest }}-\bar{x}_{\text {pretest }}}{S D_{\text {pretest }}} \quad \ldots . .1
$$

b. Jika standar deviasi tidak diketahui maka dapat dilakukan dengan uji t

$$
E S=t \sqrt{\frac{1}{n_{\text {eksperimen }}}+\frac{1}{n_{\text {kontrol }}}} \quad \ldots . .2
$$

c. Rata-rata dan standar deviasi two group pre-

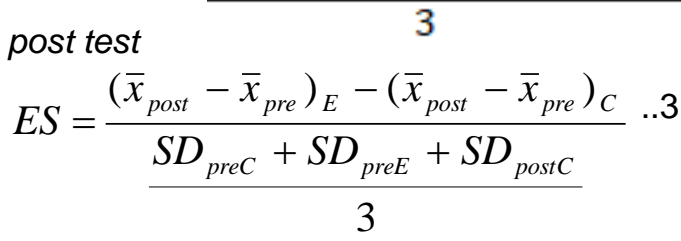

Keterangan :

$$
\begin{array}{ll}
\text { ES } & =\text { Effect size } \\
X_{\text {postest }} & =\text { Rata-rata posttest } \\
X_{\text {pretest }} & =\text { Rata-rata pretest } \\
S D_{\text {pretest }} & \text { Standar Deviasi } \\
X_{E} & =\text { Rata-rata kelompok eksperimen } \\
X_{C} & =\text { Rata-rata kelompok kontrol } \\
\mathrm{t} & =\text { Nilai } \\
\mathrm{n} & =\text { Jumlah sampel } \\
X_{\text {post }} & =\text { Rata-rata posttest kelompok } \\
\text { eksperimen } &
\end{array}
$$


$X_{\text {preE }}=$ Rata-rata pretest kelompok eksperimen

$X_{\text {postc }}=$ Rata-rara posttest kelompok kontrol

$X_{\text {prec }}=$ Rata-rata pretest kelompok kontrol

$S D_{E}=$ Standar Deviasi kelompok eksperimen

$S D_{C} \quad=$ Standar Deviasi kelompok kontrol

Dengan kriteria ukuran effect size adalah sebagai berikut (Cohen's, 1988):

Tabel 1. Kriteria Effect Size

\begin{tabular}{cc}
\hline Effect Size & Kategori \\
\hline ES $<0,2$ & Kecil \\
\hline $0,2<\mathrm{ES}<0,8$ & Sedang \\
\hline $\mathrm{ES}>0,8$ & Tinggi \\
\hline
\end{tabular}

\section{HASIL DAN PEMBAHASAN}

Hasil penelitian ini terdiri atas empat kategori, yaitu pengaruh model problem based learning ditinjau dari motivasi belajar, keterampilan proses sains, tingkatan kelas, dan materi pembelajaran. Agar lebih mudah dipahami keempat hasil analisis terhadap 18 artikel terkait model problem based learning dapat dilihat pada Tabel 2.

Tabel 2. Deskripsi Artikel yang Dianalisis

\begin{tabular}{|c|c|c|c|c|}
\hline No & $\begin{array}{c}\text { Sumber } \\
\text { Artikel }\end{array}$ & $\begin{array}{l}\text { Kode } \\
\text { Jurnal }\end{array}$ & $\begin{array}{l}\text { Tahun } \\
\text { Terbit }\end{array}$ & Tipe Jurnal \\
\hline 1. & $\begin{array}{l}\text { Halimatus, } \\
\text { dkk }\end{array}$ & K1 & 2016 & Nasional \\
\hline 2. & Erni, dkk & $\mathrm{K} 2$ & 2020 & Nasional \\
\hline 3. & $\begin{array}{l}\text { Herlinda, } \\
\text { dkk }\end{array}$ & K3 & 2017 & Nasional \\
\hline 4. & $\begin{array}{l}\text { I Made, } \\
\text { dkk }\end{array}$ & K4 & 2019 & Nasional \\
\hline 5. & Muhajirin & K5 & 2018 & Nasional \\
\hline 6. & $\begin{array}{c}\text { Fahrunnis } \\
\text { a, dkk }\end{array}$ & K6 & 2017 & Nasional \\
\hline 7. & $\begin{array}{l}\text { Hasanudd } \\
\text { in, dkk }\end{array}$ & K7 & 2016 & Nasional \\
\hline 8. & $\begin{array}{c}\text { Aweke, } \\
\text { dkk }\end{array}$ & K8 & 2016 & $\begin{array}{l}\text { Internasion } \\
\text { al }\end{array}$ \\
\hline 9. & Prayekti & K9 & 2016 & $\begin{array}{c}\text { Internasion } \\
\text { al }\end{array}$ \\
\hline 10. & $\begin{array}{l}\text { Agnes, } \\
\text { dkk }\end{array}$ & K10 & 2016 & Nasional \\
\hline 11. & Ari, dkk & K11 & 2016 & Nasional \\
\hline 12. & Nurul, dkk & $\mathrm{K} 12$ & 2017 & Nasional \\
\hline 13. & $\begin{array}{c}\text { Masyuri, } \\
\text { dkk }\end{array}$ & K13 & 2017 & Nasional \\
\hline 14. & $\begin{array}{l}\text { Kurnia, } \\
\text { dkk }\end{array}$ & K14 & 2018 & Nasional \\
\hline 15. & Silvia, dkk & K15 & 2018 & Nasional \\
\hline 16. & $\begin{array}{l}\text { Hidayatul, } \\
\text { dkk }\end{array}$ & K16 & 2020 & Nasional \\
\hline 17. & $\begin{array}{c}\text { Andini, } \\
\text { dkk }\end{array}$ & K17 & 2019 & Nasional \\
\hline
\end{tabular}

\begin{tabular}{cccc}
\hline 18. Ammalia, & K18 & 2020 & $\begin{array}{c}\text { Internasion } \\
\text { alk }\end{array}$ \\
\hline
\end{tabular}

Berdasarkan Tabel 2 dapat dilihat deskripsi dari artikel dan diketahui effect size masing-masing artikel tentang pengaruh model problem based learning terhadap motivasi belajar dan keterampilan proses sains fisika siswa SMA. Artikel yang dianalisis diberikan kode untuk masing-masingnya dan dari artikel yang dianalisis diperoleh beberapa data.

Hasil pertama dari analisis effect size ini terkait dengan pengaruh model problem based learning ditinjau dari motivasi belajar fisika siswa SMA. Rata-rata effect size yang diperoleh adalah 0,73 , untuk masing-masing effect size dari artikel dapat dilihat pada Gambar 1.

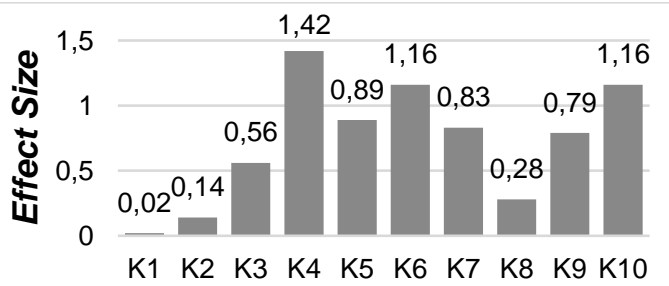

\section{Motivasi Belajar}

\section{Gambar 1. Effect size Pada Motivasi Belajar}

Dari Gambar 1 diketahui effect size pada motivasi belajar fisika siswa SMA terdapat pada 10 artikel yang dianalisis dengan kode masing-masing artikel. Pada jurnal tersebut effect size terendah dengan nilai effect size 0,02 didapatkan pada artikel kesatu (K1), sedangkan effect size tertinggi didapatkan pada artikel keempat (K4) dengan nilai effect size 1,42. Pembelajaran Berbasis Masalah atau Problem Based Learning (PBL) adalah salah satu model pembelajaran yang dapat digunakan untuk mengembangkan pola pikir siswa dan membuat siswa menjadi aktif. Siswa mengkonstruksi sendiri pengetahuan dan keterampilan baru ketika siswa tersebut belajar (Muslich, 2008).

Model problem based learning mengembangkan keterampilan berpikir siswa melalui fakta maupun kemampuan berpikir rasional, sehingga latihan yang berulang-ulang dapat membina keterampilan intelektual sekaligus dapat memotivasi siswa dalam belajar. Model problem based learning menjadikan siswa ikut berperan aktif dalam proses mencari informasi, menyelesaikan masalah yang ada, bertanggung jawab terhadap tugas yang diberikan dan bisa mengaitkan suatu konsep fisika dengan peristiwa yang ada pada kehidupannya. Model problem based learning akan membuat kegiatan belajar lebih menyenangkan, 
meningkatkan interaksi belajar dan siswa menjadi terlibat langsung dalam proses penguasaan materi. Dengan keterlibatan siswa maka motivasi belajar siswa akan meningkat (Yana, dkk; 2014).

Hasil kedua dari analisis effect size ini terkait pengaruh model problem based learning ditinjau dari keterampilan proses sains fisika siswa SMA. Rata-rata effect size yang diperoleh adalah 0,62 untuk masing-masing effect size dari artikel dapat dilihat pada Gambar 2.

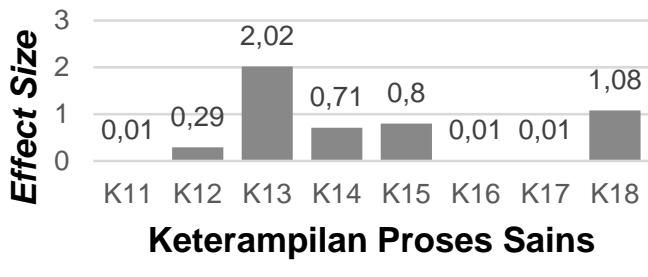

\section{Gambar 2. Effect Size Pada KPS}

Dari Gambar 2 diketahui effect size pada keterampilan proses sains fisika siswa SMA terdapat pada 8 artikel yang dianalisis dengan kode masing-masing artikel. Pada jurnal tersebut effect size terendah dengan nilai ukuran efek 0,01 didapatkan pada artikel kesebelas (K11), keenam belas (K16) dan ketujuh belas (K17), sedangkan effect size tertinggi didapatkan pada artikel ketiga belas (K13) dengan nilai effect size 2,02. Karena pada model problem based learning siswa dihadapkan masalah autentik sehingga siswa dapat menyusun pengetahuannya sendiri serta menumbuh kembangkan keterampilan yang tinggi (Angela, 2013). Kelebihan model problem based learning sebagai suatu model pembelajaran adalah realistik dalam kehidupan siswa, konsep sesuai dengan kebutuhan siswa, memupuk sifat inkuiri siswa, resensi konsep jadi kuat, dan memupuk kemampuan pemecahan masalah yang sesuai..

Hal ini mengindikasikan bahwa dalam keterampilan proses sains siswa yang belajar dengan menggunakan model pembelajaran problem based learning memberikan hasil yang lebih optimal dibandingkan siswa yang belajar tidak menggunakan model pembelajaran. Pada pembelajaran dengan model pembelajaran problem based learning, ada lima tahapan yaitu mengorientasi siswa kepada masalah, mengorganisasi siswa untuk belajar, membimbing penyelidikan, mengembangkan dan menyajikan hasil karya, dan menganalisis dan mengevaluasi proses pemecahan masalah (Rusman, 2012). Secara umum, problem based learning bertumpu pada pengembangan kemampuan berpikir siswa melalui latihan penyelesaian masalah, dan setiap siswa dilibatkan dalam proses maupun perolehan produk penyelesaiannya. Pengetahuan dan keterampilan akan ditemukan oleh siswa dengan cara mereka sendiri, jika guru merancang proses pembelajaran yang merujuk pada kegiatan menemukan (Taher, 2013). Jadi model problem based learning berpengaruh terhadap peningkatan keterampilan proses sains siswa, karena siswa yang menemukan sendiri konsep yang dipelajarinya secara langsung melalui kegiatan ilmiah sehingga konsep-konsep tersebut akan lebih mudah dipahami dan akan melekat pada pikiran siswa dan sulit untuk dilupakan (Kosim \& Verawati, 2020)

Hasil ketiga dari analisis effect size ini terkait pengaruh problem based learning ditinjau dari tingkatan kelas dapat dilihat pada Gambar 3.

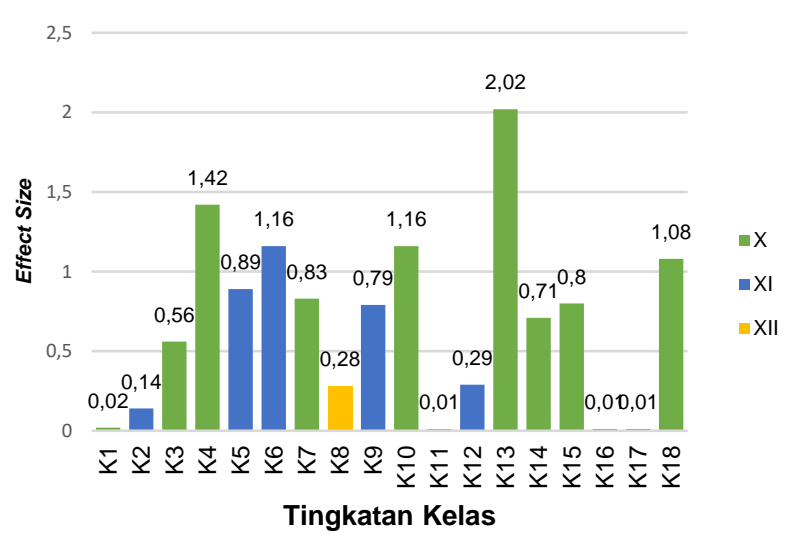

Gambar 3. Effect Size Pada Tingkatan Kelas

Pengaruh model pembelajaran problem based learning terhadap motivasi belajar dan keterampilan proses sains ditinjau dari tingkatan kelas $\mathrm{X}, \mathrm{XI}$, dan XII. Pada tingkatan kelas $X$ terdiri dari 10 artikel dengan rata-rata effect size 0,86 kategori tinggi. Tingkatan kelas $\mathrm{XI}$ terdiri dari 7 artikel dengan rata-rata effect size 0,47 kategori sedang. Tingkatan kelas XII terdiri dari 1 artikel dengan rata-rata effect size 0,28 kategori sedang.

Hasil keempat dari analisis effect size ini terkait pengaruh model pembelajaran problem based learning ditinjau dari materi pembelajaran dapat dilihat pada Gambar 4. 


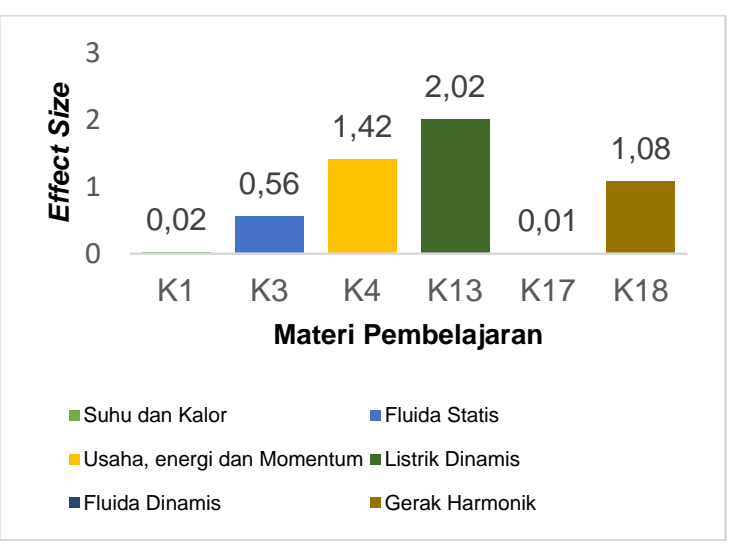

Gambar 4. Effect Size Pada Materi

Pengaruh model pembelajaran problem based learning terhadap motivasi belajar dan keterampilan proses sains siswa terdapat 6 materi pembelajaran. Materi listrik dinamis memiliki rata-rata effect size tertinggi pada artikel ketiga belas (K13) dengan nilai 2,02 dengan kategori tinggi.

\section{SIMPULAN DAN SARAN}

Berdasarkan data yang telah dianalisis dapat diambil kesimpulan dari penelitian ini. Kesimpulan dari penelitian ini yaitu : 1) model pembelajaran problem based learning memberikan pengaruh terhadap motivasi belajar fisika siswa SMA dengan rata-rata effect size 0,73 kategori sedang, 2) model pembelajaran problem based learning memberikan pengaruh terhadap keterampilan proses sains siswa dengan effect size 0,62 kategori sedang, 3) model pembelajaran problem based learning memberikan pengaruh terhadap motivasi belajar dan keterampilan proses sains fisika pada tingkatan kelas $\mathrm{X}, \mathrm{XI}$ dan XII dengan effect size 0,86 kategori tinggi, 0,47 kategori sedang dan 0,28 kategori sedang, dan 4) model pembelajaran problem based learning memberikan pengaruh terhadap motivasi belajar dan keterampilan proses sains pada materi listrik dinamis dengan effect size 2,02 kategori tinggi.

\section{DAFTAR RUJUKAN}

Agnes Mawar Yunita Sihombing dan Eidi Sihombing. (2016). The Effect Of Problem Based Learning Model And Motivation To Learn Physics On Student's Learning Outcomes Of Heat And Temperature Topic In Class X Sma Negeri 1 Tebing Tinggi Academic Year 2014/2015. Jurnal Inpafi.

Ammalia Nurjannah, Abdul Gani, Evendi Evendi, Muhammad Syukri, Elisa Elisa. (2020). Question webs-based learning: Science process skills and scientific questioning skills of students on harmonic motion topic . Momentum: Physics Education Journal 4(1), 38-48.

Andini Prameswari, Wahyudi. (2019). Pembelajaran Fisika Menggunakan Model Problem Based dan Model Project Based Learning Ditinjau dari Keterampilan Proses Sains Siswa pada Materi Fluida Dinamis Kelas XI SMA Panca Bhakti Pontianak . Jurnal Pendidikan Sains dan Aplikasinya (JPSA) 2(2), 25-30.

Angela, M. (2013). Pengembangan Buku Ajar Bermuatan Nilai-Nilai Karakter Pada Materi Usaha dan Momentum Untuk Pembelajaran Fisika Siswa Kelas XI SMA. Pillar of Physics 1, 63-70.

Arends, R. I. (2008). Learning To Teach: Belajar Untuk Mengajar . Yogyakarta: Pustaka Belajar.

Ari Gita Prahmana Putra, Singgih Bektiarso. (2016). Pengaruh Model Problem Based Learning (PBL) Terhadap Hasil Belajar Dan Keterampilan Proses Sains Dalam Pembelajaran Fisika Di SMA (Kelas X SMA Negeri 3 Jember) . Jurnal Pembelajaran Fisika 5(2), 129-134.

Asrizal, A., Amran, A., Ananda, A.,, Fetiyed, F. . (2018). Development of adaptive contextual teaching model of integrated science to improve digital age literacy on grade VIII students. Journal of Physics : Conferences Series 1116032004.

Aweke Shishigu Argaw, Beyene Bashu Haile, Beyene Tesfaw Ayalew, Shiferaw Gadisa Kuma. (2016). The Effect Of Problem Based Learning (PBL) Instruction On Students' Motivation And Problem Solving Skills Of Physics. EURASIA Journal of Mathematics Science and Technology Education, 857-871.

Becker, K. \& Park, K. (n.d.). Effects Of Integrative Approaches Among Science, Technology, Engineering, And Mathematics (STEM) Subjects On Students' Learning: A Preliminary Metaanalysis. Journal Of STEM Education, 12 (1), 2011.

Cohen, J, (1988). Statistiical Power Analysis for the Behavior Sciences. Hillsdale NJ. Erlbaum Associates. Jurnal Penelitian. 14 (1).

Erni Sriwahyuni, Iskandar Wiryokusumo, Hari Karyono. (2020). Keefektifan Model Pembelajaran Problem Based Learning Terhadap Motivasi dan Hasil Belajar. Journal of Education Technology 4(1), 80-87. 
F Mufit, Asrizal, S A Hanum and A Fadhilah. (2020). Preliminary research in the development of physics teaching materials that integrate new literacy and disaster literacy. The 2nd International Conference on Research and Learning of Physics, 1-12.

Fahrunnisa, Muhammad Arsyad, Muis. (2017). Pengaruh Model Pembelajaran Berbasis Masalah Terhadap Motivasi Belajar Fisika Dan Hasil Belajar Pada Peserta Didik Kelas XI SMAN 13 Makassar.

Halimatus Sakdiah Pelawi dan Karya Sinulingga. (2016). Pengaruh Model Problem Based Learning Dan Motivasi Belajar Terhadap Hasil Belajar Siswa Di Kelas X SMA Swasta Sinar Husni . Jurnal Pendidikan Fisika 5(1), 32-37.

Hasanuddin, Sidin Ali, Muh Arsyad. (2016). Pengaruh Model Pembelajaran Berbasis Masalah Dan Motivasi Terhadap Hasil Belajar Fisika Peserta Didik Kelas X SMA Negeri 18 Makassar.

Herlinda, Eko Swistoro dan Eko Risdianto. (2017). Pengaruh Model Problem Based Learning (Pbl) Terhadap Hasil Belajar, Kemampuan Pemecahan Masalah Fisika Dan Minat Belajar Siswa Pada Materi Fluida Statis Di SMAN 1 Lebong Sakti. Jurnal Pembelajaran Fisika 1(1) , 1-10.

Hidayatul Aini, Sutrio, Aris Doyan. (2020). Pengaruh Model Pembelajaran Perolehan Konsep Berbasis Masalah Terhadap Kemampuan Pemecahan Masalah Dan Pemahaman Konsep Fisika Peserta Didik Kelas XI MIA MAN 1 Mataram . ORBITA. Jurnal Hasil Kajian, Inovasi, dan Aplikasi Pendidikan Fisika 6(1), 181-187.

I Made Yuda Suryawan, I Wayan Santyasa \& I Gede Aris Gunadi . (2019). Keefektifan Model Problem Based Learning dan Motivasi Berprestasi Siswa dalam Pencapaian Prestasi Belajar Fisika. MIMBAR PENDIDIKAN: Jurnal Indonesia untuk Kajian Pendidikan 4(1), 35-54.

Kosim, Sumarni., \& Verawati, N. N. S. P. (2020). Pengaruh Model Pembelajaran Inkuiri Terbimbing Berbantuan Simulasi Virtual Terhadap Penguasaan Konsep Fisika Peserta Didik SMA. Jurnal Pendidikan Fisika dan Teknologi (JPFT) 6(2), 220-227.

Kurnia Saputri, Muhammad Muslim, dan Murniati. (2018). Pengaruh Model Problem Based Learning Terhadap
Keterampilan Menyimpulkan Hasil Percobaan Siswa Pada Pembelajaran Fisika Di Kelas X SMA Negeri 1 Tanjung Lubuk. Jurnal Inovasi Dan Pembelajaran Fisika , 1-8.

Lasmawan, W. (2010). Menelisik Pendidikan IPS dalam Perspektif Kontekstual Empiris. Singaraja: Mediakom Indonesia Press Bali.

Maradona. (2013). Analisis Keterampilan Proses Sains Siswa Kelas XI IPA SMA Islam Samarinda pada pokok bahasan hidrolisis melalui metode Eksperimen. Prosiding Seminar Nasional Kimia, 6270.

Masyhuri , Albertus Djoko Lesmono, Rif'ati Dina Handayani. (2017). "Model Problem Based Learning (PBL) Disertai Tugas Dalam Pembelajaran Fisika Di SMA" (Pokok Bahasan Listrik Dinamis). Jurnal Pembelajaran Fisika 6(4), 418426.

Muhajirin. (2018). Pengaruh Model Problem Based Learning Terhadap Motivasi Dan Hasil Belajar Fisika Peserta Didik SMA Negeri 1 Parangloe Kabupaten Gowa . Seminar Nasional Fisika 2018, 1-6.

Muslich, M. (2008). KTSP Pembelajaran Berbasis Kompetensi dan Kontekstual. Jakarta: Bumi Aksara.

Nurul Hikmawati, Sutrio, Hikmawati. (2017). Pengaruh Model Pembelajaran Berbasis Masalah Dengan Pembekalan Pengetahuan Awal Terhadap Keterampilan Proses Sains Peserta Didik SMA . Jurnal Pendidikan Fisika dan Teknologi 3(1), 92-100.

PISA. (2015). Released Item Descriptions. (Online).

Prayekti. (2016). Effects of Problem-Based Learning Model Versus Expository Model and Motivation to Achieve for Student's Physic Learning Result of Senior High School at Class XI. Journal of Education and Practice, 30-37.

Rusman. (2012). Model-Model Pembelajaran Mengembangkkan Profesionalisme Guru. Jakarta: Raja Grafindo Persada.

S R Anori, F Mufit and Asrizal. (2021). Validity and practicality book chapter's model on thermodynamics and mechanical waves material integrated new literacy and disaster literacy of students for grade XI high school . 3rd International Conference on Research and Learning of Physics (ICRLP) 2020, 1-9.

Silvia Anggri Wijaya, Rosane Medriati, Eko Swistoro. (2018). Pengaruh Model Pembelajaran Berbasis Masalah terhadap Kemampuan Pemecahan 
Masalah Fisika dan Sikap IImiah Siswa di SMAN 2 Kota Bengkulu. Jurnal Kumparan Fisika 1(3) , 28-35.

Taher, M. (2013). Retrieved from Implementasi Penilaian Sikap Pada Pembelajaran Kurikulum 2013: (http://sumut.kemenag.go.id/file/

Toharudin, U. Hendrawati, S \& Rustaman, A. (2011). Membangun Literasi Sains Peserta Didik. Bandung: Humaniora.

Usmeldi, U., Amini, R., \& Trisna, S. . (2017). The development of research-based learning model with science, environment, technology, and society approaches to improve critical thinking of students. Jurnal Pendidikan IPA Indonesia, 6(2), 318-2325.

Wardhani, K., Sunarno, W.,\& Suparmi. (2012). Pembelajaran Fisika dengan Model Problem Based Learning Menggunakan Multimedia dan Model Ditinjau dari Kemampuan Verbal Siswa . Jurnal Pendidikan Sains Program Pasca Sarjana Universitas Sebelas Maret Surakarta.

Yana Dirza Amalia, Asrizal, Zulhendri Kamus. (2014). Pengaruh Penerapan LKS Berorientasi Pembelajaran Berbasis Masalah Terhadap Kompetensi Siswa Kelas X SMA Negeri 1 Gunung Talang. Pillar Of Physics Education 4, 17-24. 